\title{
EVALUATION OF BODY IMAGE AND SELF-CONCEPT AND THEIR CORRELATION WITH DEPRESSIVE SYMPTOMS IN PARKINSON'S DISEASE
}

\author{
Ariane Haydée Estrada Gamarra', Cibele Silva Molski ${ }^{1}$, Arlete Hilbig ${ }^{2}$, Cristina Kern Valentini ${ }^{3}$, \\ Vera Lúcia Widniczck Striebel ${ }^{4}$, Carlos Roberto de Mello Rieder ${ }^{5}$
}

\begin{abstract}
Objective: To identify characteristics of body image and self-concept in individuals over fifty years of age with Parkinson's disease (PD). The secondary objectives are to analyze whether body image and selfconcept are influenced by the severity of PD and to verify if there is correlation between depression, selfconcept and body image in cases of PD. Method: Participating in the study were 48 individuals, being 26 with PD and 22 Controls. The instruments used were: The Mini Exam of Mental State, The My Body Image Test, The Factorial Self-concept Test, The Beck Depression Inventory, the motor section of The Unified Parkinson's Disease Rating Scale and The Modified Hoehn and Yahr Scale. Results: In PD the perception of body image and self-concept demonstrated significantly reduced values $p<0.001$ and $p=0.012$ respectively, and the presence of depression symptomatology was significantly more $(p=0.002)$. Conclusion: Individuals with PD present alteration of body image and self-concept and also present lower personal confidence and lower social receptivity, correlated with depressive symptoms.
\end{abstract}

KEY WORDS: Parkinson's disease, body image, self-concept, depression, physiotherapy.

\section{Avaliação da imagem corporal, autoconceito e suas correlações com os sintomas depressivos na doença de Parkinson}

Resumo - Objetivo: Identificar características de imagem corporal e autoconceito em indivíduos com doença de Parkinson (DP) acima de cinqüenta anos de idade. Os objetivos secundários são analisar se a imagem corporal e o autoconceito são influenciados pela gravidade da DP e, verificar se existe correlação entre depressão, autoconceito e imagem corporal na DP. Método: Participaram do estudo 48 indivíduos, sendo 26 com DP e 22 Controles. Os instrumentos utilizados foram: Mini-Exame do Estado Mental, Teste A Minha Imagem Corporal, Escala Fatorial de Autoconceito, Inventário de Depressão de Beck, Unified Parkinson's Disease Rating Scale parte motora e Hoehn e Yahr Modificada. Resultados: Na DP a percepção da imagem corporal e do autoconceito, demonstraram valores reduzidos significativamente $(p<0.001$ e $p=0.012)$ respectivamente, e a sintomatologia depressiva apresentou-se significativamente maior $(p=0.002)$. Conclusão: Indivíduos com DP apresentam alteração da imagem corporal e do autoconceito, apresentaram também menos confiança pessoal e menor receptividade social correlacionados com sintomas depressivos.

PALAVRAS-CHAVE: doença de Parkinson, imagem corporal, autoconceito, depressão, fisioterapia.

Parkinson's disease (PD) is a degenerative and progressive disease of the central nervous system (CNS), which is characterized by the death of neurons in the substantia nigra, with consequent diminution of dopamine, lead- ing to typical motor alterations', such as tremor, rigidity, slowness of voluntary movements and walking and posture balance alterations ${ }^{2}$. In addition, patients with PD may present neurobehavioral alterations such as demen-

\footnotetext{
'IPA Methodist University Center, Porto Alegre RS, Brazil; ${ }^{2}$ Neurology Service, Movement Disorders Clinic, Complex Hospital Santa Casa of Porto Alegre RS, Brazil; ${ }^{3}$ Psychology Lecturer, Psychology Course, IPA Methodist University Center, Porto Alegre RS, Brazil; ${ }^{4}$ Neurofunctional Physiotherapy, Physiotherapy Course, IPA Methodist University Center, Porto Alegre RS, Brazil; ${ }^{5}$ Neurology Service, Movement Disorders Clinic, Hospital of Clinicas of Porto Alegre RS, Brazil.
}

Received 28 October 2008, received in final form 26 May 2009. Accepted 18 June 2009.

Dra. Ariane Haydée Estrada Gamarra - Avenida Benno Mentz 105/101 - 91370-020 Porto Alegre RS - Brasil. E-mail: arianegamarra@yahoo.com.br or csmolski@gmail.com 
tia, depression and isolation an tendency ${ }^{3}$.PD is one of the most prevalent chronic neurological disease and its prevalence increases with aging ${ }^{4}$. Depression is present in 25 to $40 \%$ of PD patients ${ }^{5}$, which can be explained by emotional reaction to the incapacity caused by the disease or by the neurodegeneration of cerebral areas with a consequent reduction in serotoninergic, dopaminergic and noradrenergic activity ${ }^{6}$.

Any individual who is ill, who suffers from an injury that causes distortion to the body structure or experiences the effects of an injury for a prolonged time may suffer alterations to, or losses in, mental and physical functions, levels of independence and body image ${ }^{7}$. Body image consists of the picture formed by the mental images or representations of the body, which present themselves to the individual in the context of their life. It encompasses all of the forms by which a person perceives and conceives their own body, being linked to a cerebral organization, integrated with, and influenced by sensory factors, development processes and psychodynamic aspects. The process of development of the body image is connected to biological, cultural, affection and environmental factors. Multiple factors may influence the process of development of the body image, such as the presence of illness, age and inappropriate social relationships, as deficiencies in the nervous system for adequately processing the mental images ${ }^{8}$. Distortions of body image are thought to be common in some pain states ${ }^{9}$. Pain may be a complain in more than $50 \%$ of PD patients ${ }^{10}$. It has been suggested that if body image relates to pain, treating body image may reduce pain, and treating pain may normalize body image $\mathrm{e}^{9,10}$. A neurological dysfunction could unleash not only alterations in the body image because of the illness itself, but also because of the reaction of the individual who, to preserve their body image, ends up modifying their body image depending on the perceived experiences resulting from the dysfunction suffered. Hence, it has been emphasized that the alterations in the body image arising from cerebral pathology need to be analyzed not only considering the comprehension of cerebral physiology, but also taking into consideration the psychological structure and its alterations resulting from the experiences lived by the individual ${ }^{1 "}$.

Individuals have been investigated by the measure in which they are influenced not only by the nature of the disease itself and the conception that they have of its causes, but also by the secondary or indirect consequences such as restriction of activities, medicines, diets, surgical interventions and hospital admissions. The impact on family life is also emphasized, having, as a result, multiple effects over the body image ${ }^{12}$. Body image forms part of the self-concept ${ }^{7}$ that has been defined as the mental representations of the personal characteristics utilized by the individual for the definition of him or herself and reg- ulation of his or her behavior ${ }^{12}$. The diminution of physical capacity, the appearance of disease and other negative factors that happen at advanced age are also factors that, in general, devalue the self-concept of the individual $^{13}$. While the exact relationship is still not clear, this data points to evidence of alteration in the perceptions of body image and self-concept in individuals with some disease, such as PD, since the physical, psychological and social states interfere both in these concepts and in the evolutionary process of the disease. Depressive symptom present in PD patients may be related to the alterations in body image and self-concept. Many patients experience negative feelings towards their body and, in general, negative psychological experiences related to the physical limitations ${ }^{14}$. The improvement of the body awareness through experiencing the body itself and its interrelationship with movement may help the rehabilitation process for these individuals.

The objective of this study is to identify characteristics of body image and self-concept in individuals above fifty years of age with PD and the relationship with the functional composition of the illness and symptoms of depression.

\section{METHOD}

Participants in this study were individuals with Parkinson's disease diagnosed by a neurologist of Complexo Hospitalar Santa Casa de Porto Alegre or of the Hospital de Clínicas de Porto Alegre in accordance with the Criteria for the Diagnosis of Parkinson's Disease of the Parkinson's Disease Society Brain Bank, London ${ }^{15}$.

All the included individuals were above fifty years of age and were in the stage I and IV of the modified Hoehn and Yahr staging scale $e^{16-17}$. Exclusion criteria were as follows: (1) vascular, pharmacological or atypical parkinsonism; (2) presence of other neurological or psychiatric diseases nonrelated to PD; (3) abusive use of alcohol or illicit drugs; (4) any serious clinical disease able of produce functional impairment; (5) Mini-Mental Score Examination (MMSE) lower than 19 points ${ }^{18}$ and (6) non literate person. The control group was formed by individuals selected from the community that apart from PD fill the same inclusion and exclusion criteria. All participants gave their written informed consent to participate in the study, which was approved by the Ethics Committees of the Centro Universitário Metodista IPA, Complexo Hospitalar Santa Casa de Porto Alegre and Hospital de Clínicas de Porto Alegre, in accordance with National and International Directives and Regulations, especially Resolution 196/96, and those related, of the National Health Council.

Patients who met criteria for the study were scheduled for clinical assessment, including disease severity as measured by the Hoehn and Yahr Scale ${ }^{15}$ and the motor section of the Unified Parkinson's Disease Rating Scale (UPDRS) ${ }^{19}$. In both groups, the participants were assessed by the Factorial Self-concept Scale questionnaires $^{20}$, the The My Body Image Test ${ }^{21}$ and the Beck Depression Inventory ${ }^{22}$. 
Table 1. Characteristics of control subjects and PD patients.

\begin{tabular}{lccc}
\hline & $\begin{array}{c}\text { Parkinson's disease group } \\
\text { Variables }\end{array}$ & $\begin{array}{c}\text { Control group } \\
\mathrm{n}=26(54.2 \%)\end{array}$ & $\mathrm{p}$ \\
\hline Sex M/F (n/\%) & $15(57.7 \%) / 11(42.3 \%)$ & $13(59.1 \%) / 9(40.9 \%)$ & 0.923 \\
Age (mean/SD) & $67.3( \pm 8.9)$ & $66.4( \pm 8.3)$ & 0.737 \\
MEEM (mean/SD) & $26.6( \pm 3.1)$ & $28.6( \pm 1.4)$ & 0.006 \\
\hline
\end{tabular}

n: sample size; SD: standard deviation; p: significance level; M: male; F: female; MEEM; Mini-Exam of Mental State.

Table 2. Comparison of Body Image Perception and Auto-concept betwen PD patients and Control.

\begin{tabular}{lccc}
\hline Variables & $\begin{array}{c}\text { Parkinson's disease group } \\
(\mathrm{n}=26) \text { mean / SD }\end{array}$ & $\begin{array}{c}\text { Control group }(\mathrm{n}=22) \\
\text { mean / SD }\end{array}$ & $\mathrm{p}$ \\
\hline TMIC & $51.1( \pm 12.5)$ & $71.9( \pm 9.1)$ & $<0.001$ \\
BDI & $13.5( \pm 7.3)$ & $6.7( \pm 6.5)$ & 0.002 \\
Self-concept Scale Score & $508.1( \pm 41.5)$ & $547.3( \pm 61.2)$ & 0.012 \\
Self-concept Scale Domains & & & 0.001 \\
$\quad$ Self Personal - Security & $72.6( \pm 12.0)$ & $86.2( \pm 14.8)$ & 0.568 \\
Self Social - Social Attitude & $60.2( \pm 8.3)$ & $62.0( \pm 12.6)$ & 0.416 \\
Self Personal - Self-Control & $90.8( \pm 10.8)$ & $93.8( \pm 14.5)$ & 0.959 \\
Self Ethical - Moral & $113.8( \pm 8.8)$ & $113.1( \pm 7.6)$ & 0.179 \\
Self Somatic & $66.6( \pm 9.0)$ & $70.4( \pm 9.7)$ & 0.002 \\
Self Social - Social Receptivity & $102.8( \pm 17.3)$ & $119.6( \pm 17.1)$ & \\
\hline
\end{tabular}

n: sample size; SD: standard deviation; p: significance level; TMIC: My Body Image Test; BDI: Beck Depression Inventory.

The Factorial Self-Concept Scale ${ }^{20}$ is a psychometric instrument for the evaluation of self-concept validated to the Brazilian population. This instrument is composed of 79 items grouped in 6 domains of Self (Personal-Security, Social Attitude, Ethical - Moral, Somatic and Social Receptivity). The My Body Image Test ${ }^{21}$ is a test that focuses on the way in which a person sees and feels their body, evaluated with 16 items graduated from 0 to 5 that refer to the physical condition; body's abilities; health and appearance. The Beck Depression Inventory (BDI) ${ }^{22}$ is an instrument that assess depressive symptomatology.

\section{Statistical analysis}

Descriptive statistics were carried out for the proposed variables by means of the program SPSS for windows (version 13.0). To describe the data, frequency calculations were carried out for the category variables and mean and standard deviation for the continuous variables. To compare the mean of the groups, the Student's t-test was conducted. To verify the relationship between continuous variables, the Pearson correlation coefficient was used. To verify the association between category variables the Pearson Chi-squared test was used. The significance level was considered when $\mathrm{p}<0.05$.

\section{RESULTS}

\section{Characteristics of the study population}

Twenty-six patients and twenty two controls were studied. Demographics data are shown in Table 1. The av- erage duration of disease was $8.0 \pm 5.2$ years. The mean score on the Hoehn and Yahr Scale was $2.3 \pm 0.6$ and the mean score of UPDRS III was 30.1 \pm 14 .3. The mean score of the Mini Exam of Mental State of individuals control was $28.6 \pm 1.4$ and $26.6 \pm 3.1$ of PD patients.

\section{Body image, auto-concept and depression}

The PD patients presented lower scores (worse perception) in the evaluation of perception of body image evaluated by The My Body Image Test (51.1 \pm 12.5$)$ than control individuals (71.9 \pm 9.1$)$. This was statistically significant $(p<0.001)$. The perception of self-concept also appeared reduced in the PD group. The mean of The Factorial SelfConcept Scale score was 508.1 \pm 41.5 in PD patients and and $547.3 \pm 61.2$ in control group ( $p=0.012$ ). Analysis of the different domains of The Factorial Self-Concept Scale (Personal-Security, Social Attitude, Ethical - Moral, Somatic and Social Receptivity) the domains of personal security $(p=0.001)$ and social receptivity $(p=0.002)$ appeared to be significantly the most negatives in the formation of self-concept (Table 2). The depressive symptoms evaluated by the BDI appeared greater $(p=0.002)$ in the PD group (13.5 \pm 7.3$)$ than in the control group $(6.7 \pm 6.5)$ (Table 2).

\section{Correlation between the body image and} self-concept scales with the severity of PD

There was not a statistically significant correlation 


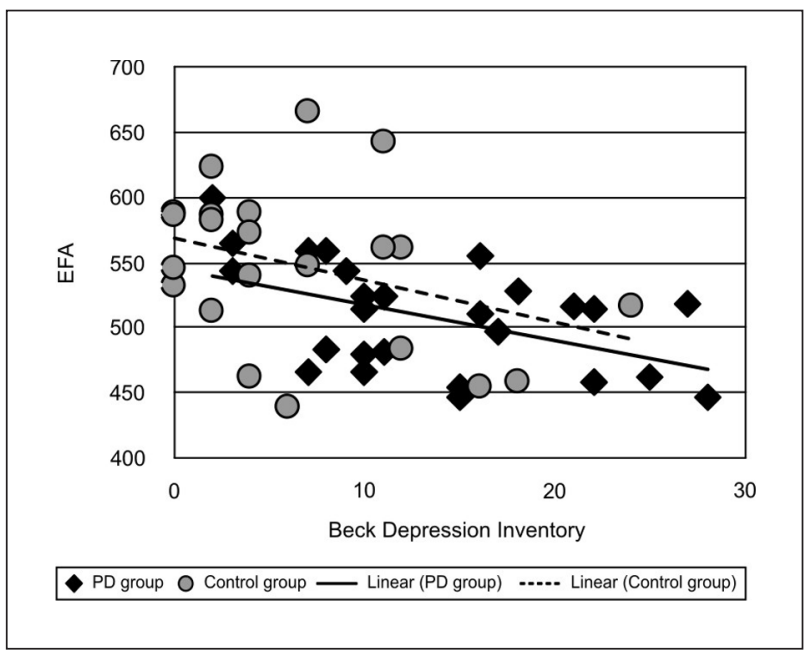

Fig 1. Correlation between self-concept and depressive symptoms in PD and control. EFA: Factorial Self-concept Scale; PD; Parkinson's disease.

between the evaluation of body image (My Body Image test) and self-concept (Factorial Self-concept Scale) with the stage of the disease (Modified Hoehn and Yahr Scale), the level of motor impairment (UPDRS motor part) or the time of illness.

\section{Correlation between self-concept}

and body image with depression

In the PD group, a significant inverse correlation of moderate degree was observed between self-concept and depression ( $p=0.011$ ) with a Pearson coefficient of 0.49 (Fig 1). In addition, there was an inverse correlation, although not significant, between body image and depression $(p=0.058)$, with a Pearson coefficient of -0.37 (Fig 2). No significant correlation was observed in the control group between self-concept, body image and depression.

\section{DISCUSSION}

This is the first study that evaluated the body image perception and self-concept in PD patients through "The My Body Image Test" and "The Factorial Self-Concept Scale". The PD patients presented worse perception of their body image than control individuals. The self-concept was also reduced in PD patients in relation to controls. Interestingly there was not a correlation between the evaluation of body image and self-concept with the severity of disease, evaluated by the Hoehn and Yahr Scale and the motor UPDRS. Similarly, neither body image perception nor self concept correlated with time of disease.

As expected the depressive symptoms evaluated by the $\mathrm{BDI}$ were more marked in the PD group than in the control group and an inverse correlation between selfconcept and depression was observed. A correlation was

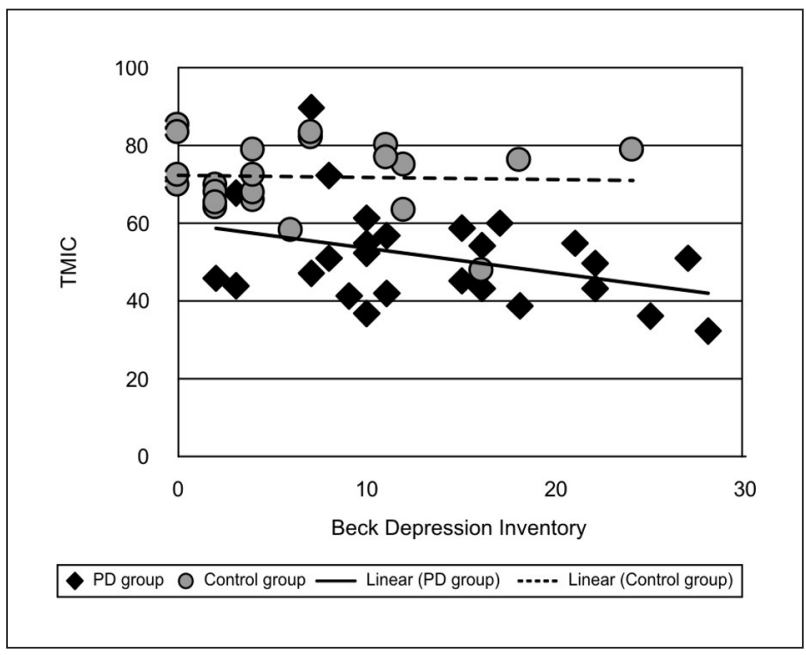

Fig 2. Correlation between body image perception and depressive symptoms in PD and control. TMIC: My Body Image Test; PD: Parkinson's disease.

also observed between the perception of body image and depressive symptoms however, that was not statistically significant. This significance probably would be obtain with a large sample. In controls individual self-concept and body image perception were not correlated with depression. A comparison with other chronic clinical conditions would be interested of being done.

The difference encountered in body image in the PD group points to a decline in the perception of physical condition, the body's abilities, health and appearance. The decline in body image was observed in other neurological conditions. In a study that evaluated hemiplegic individuals through "The My Body Image Test", these individuals presented impairment in body image perception ${ }^{21}$. The impairment in the body perception and body consciousness observed in these subjects could be due to somatosensoral and motor-perception problems that are relatively common in cerebral injuries due to what is call "perceptual confusion", a disorder in the body image due to the difficulty in perceiving or interpreting sensory input ${ }^{23}$.

It has been mention that the body dynamic and balance form part of the body image $e^{24}$. Therefore, it would be possible to explain that the reduction in the perception of body image in individuals with PD could be the result of the rigidity and the difficulty of locomotion experienced with the progression of the disease $e^{25}$. However in our study there were no correlation between the evaluation of body image with severity and time of disease. These results suggest that PD impairment in body image could be due to other factor such as CNS modifications.

It is generally accepted that the parietal lobe, specifically the right parietal lobe plays a major part in the construction of the body image. Areas 5, 7 and 40 of the pa- 
rietal lobe constitute the somesthetic association area. These areas receive an extensive input from the post-central gyrus and additionally, they have extensive reciprocal connections with the lateral nuclear group of the thalamus, including the pulvinar. The supramarginal gyrus (area 40), especially on the dominant side, is involved with the higher integration of the body image. The subcortical dopaminergic pathways may influence cortical neuronal systems in the right parietal lobe. In PD, besides the dopaminergic damage in substantia nigra, pathological and neurochemical changes have been observed in cortical and subcortical structures including the serotonergic raphe nuclei, the noradrenergic locus coeruleus and the cholinergic nucleus basalis of Meynert ${ }^{26}$. These subcortical neurotransmitter systems send diffuse projections to the neocortex and chronic deafferentation from these subcortical systems results in diminished cortical metabolic activity, especially in the posterior cerebral regions, which is more pronounced in patients with cognitive impairment. The disconnection of various subcortical regions from the neocortex and the subsequent effect on thalamocortical and corticocortical connections contributes to the development of various cognitive deficits observed in these patients including disorders of the body image ${ }^{27}$.

Self-concept in PD patients was other aspect evaluated in this study by The Factorial Self-Concept Scale. This scale contains six domains (Personal-Security, Social Attitude, Ethical - Moral, Somatic and Social Receptivity). Although in the present study was verified that there is a general alteration in the self-concept perception in PD patients, the most negative domains observed were the personal security and social receptivity.

Studies show that the physical changes that occur with aging may provoke changes on the self-concept ${ }^{28}$. Some studies have observed that health and concurrent mobility changes are the major predictors of satisfaction in old age. Individuals with PD suffer restrictions to corporal mobility that could lead to modifications of self-concept. We have observed that the impairments in the self concept observed in PD patients in relation to control group were mainly in the domain of security and social receptivity. Patients with PD perceive themselves as more insecure, hesitant, indecisive, fragile and unstable than those of the control group. The evaluation of social receptivity shows with PD appear more reserved, unpopular, disinterested, timid, solitary and sad, than those of the control group. Impairment of social receptivity in the PD group could be intimately related with the feeling of personal insecurity from which these subjects could be led to social isolation due to the difficulty of liberating themselves from the fear of relationships. These impairments in self conception, either in the security as in the social receptivity domains may be resultant more from central ner- vous modification than secondary to motor impairments once we have not found correlation of self-concept with severity and time of disease.

Depression is a common condition in PD patients ${ }^{29}$. A correlation between self-concept and depression was observed in this study. The self concept is worse in patients with more depressive symptoms and vice versa. This correlation was not observed in control group. A cause-effect conclusion is not possible by the present study. Depressive patients may have worst self-concept nevertheless a low self-concept may cause more depression symptoms. A large part of the neurological difficulty following from some type of damage to the central nervous system frequently shows as depression, as much as through the neurophysiological alterations directly implicated in the biological genesis of the depression as from the adverse consequences of the psychosocial adaptation capacity that these diseases inflict on these individual ${ }^{30}$.

To conclude, our study shows that PD patients have worse perception of their body image and of their selfconcept. Those do not depend on the severity of disease but are correlated with depressive symptoms. An adequate recognition of this condition may help to the better treatment of this disease. We suggest that new experimental studies should be conducted with the aim of verifying the efficacy of antidepressants drugs and physiotherapeutic care on the treatment of the perception of body image and of self-concept.

\section{REFERENCES}

1. Agid Y. Parkinson's disease pathophysiology. Lancet 1991;337:1321-1324.

2. Conley SC, Kirchner JT. Parkinson's disease: the shaking palsy. Underlying factors, diagnostic considerations and clinical course. Postgrad Med 1999;106:39-50

3. Cutson TM, Laub KC, Schenkman M. Pharmacologycal and nonpharmacologycal interventions in the treatment of Parkinson's disease. Phys Ther 1995;75:363-372.

4. Tanner CM, Aston DA. Epidemiology of Parkinson's disease and akinetic syndromes. Curr Opin Neurol 2000;13:427-430.

5. Okun MS, Watts RL. Depression associated with Parkinson's disease - clinical features and treatment. Neurology 2002;58:63-70.

6. Ravina B, Camicioli R, Como PG, et al. The impact of depressive symptoms in early Parkinson disease. Neurology 2007; 69:342-347.

7. Bronheim H, Strain JJ, Biller HF. Psychiatric aspects of head and neck surgery. Part II: Body image and psychiatric interventions. Gen Hosp Psychiatry 1991;13:225-232.

8. Tavares MC. Imagem corporal: conceito e desenvolvimento. Barueri (SP): Manole; 2003.

9. Lotze, M. Role of distorted body image in pain. Curr Rheumatol Reports 2007;9:488-496.

10. Silva EG, Viana MA, Quagliato EMAB. Pain in Parkinson's disease: analysis of 50 cases in a clinic of movement disorders. Arq Neuropsiquiatr 2008;66:26-29.

11. Schilder P. A Imagem do corpo: as energias construtivas da psique. São Paulo: Martins Fontes; 1999.

12. Niedenthal PM, Beike DR. Interrelated and isolated selfconcepts. Personality Social Psychol Rev 1997;1:106-128.

13. Villa Sáchez A, Escribano EA. Medição do autoconceito. Bauru (SP): EDUSP; 1999. 
14. Taleporos G, McCabe MP. Body image and physical disability: personal perspectives. Soc Sci Med 2002;54:971-980.

15. Hughes AJ, Daniel SE, Kilford L, Lees AJ. Accuracy of clinical diagnosis of idiopathic Parkinson's disease: a clinico-pathological study of 100 cases. J Neurol Neurosurg Psychiatry 1992;55:181-184.

16. Hoehn MM, Yahr MD. Parkinsonism: onset, progression and mortality. Neurology 1967;17:573-581.

17. Schenkman ML, Clark K, Xie T, Kuchibatla M, Shinberg M, Ray L. Spinal movement and performance of standing reach task in participants with and without Parkinson's disease. Phys Ther 2001;81:1400-1411.

18. Bertolucci PH, Brucki SM, Campacci SR, Juliano Y. O mini-exame do estado mental em uma população geral: impacto da escolaridade. Arq Neuropsiquiatr 1994;52:1-7.

19. Fahn S, Elton RL, and members of the UPDRS Development Committee. Unified Parkinson's Disease Rating Scale. In: Fahn S, Marsden CD, Calne D, Goldstein M (Eds). Recent developments in Parkinson's disease. Florham Park, Macmillan Healthcare Information, USA; 1987:153-163.

20. Tamayo A. EFA: Escala Fatorial de Autoconceito. Arq Bras Psicol 1981;33:87-102.

21. Lovo TMA. Adaptação e aplicação de questionários de imagem corporal em portadores de hemiplegia. Campinas (SP): UNICAMP - FEF; 2001.
22. Beck AT, Ward CM, Mandelson M. An inventory for measuring depression. Arch Gen Psychiatry 1961;4:551-571.

23. Sandyk R. Reversal of a body image disorder (macrosomatognosia) in Parkinson's disease by treatment with AC pulsed electromagnetic fields. Int J Neurosci 1998;93:43-54.

24. Alves F. Psicomotricidade: corpo, ação e movimento. $2^{\text {a }}$ Ed. Rio de Janeiro: Wak; 2003.

25. Morris ME. Movement disorders in people with Parkinson disease: model for physical therapy. Phys Ther 2000;80:578-597.

26. Halliday GM, Blumbergs PC, Cotton RGH, Blessing WW, Geffen LB. Loss of brainstem serotonin and substance P-containing neurons in Parkinson's disease. Brain Res 1990;510:104-107.

27. Eberling JL, Richardson BC, Reed BR, Wolfe N, Jagust WJ. Cortical glucose metabolism in Parkinson's disease without dementia. Neurobiol Aging 1994;15:329-335.

28. Ward R. The aging experience. Cambridge: Harper and Row; 1984.

29. Zgaljardic DJ, Borod JC, Foldi NS, Mattis P. A review of the cognitive and behavioral sequelae of Parkinson's disease: relationship to frontostriatal circuitry. Cog Behav Neurol 2003; 16:193-210.

30. Teng CT, Humes EC, Demetrio FN. Depressão e comorbidades clínicas. Rev Psiq Clin 2005;32:149-159. 